in the heterosexual population is to be prevented intervention should focus primarily on injecting drug users and their partners who continue to engage in unprotected heterosexual intercourse.

Since this paper was prepared a number of seroconversions attributed to needle sharing have occurred in a Scottish prison. At least one of our group is involved.

This study is funded by the Medical Research Council.
1 Robertson JR, Bucknall ABV, Welsby PD, Roberts JJ, Inglis JM, Peutherer F, et al. Epidemic of AIDS related virus (HTLV-111/LAV) infection among intravenous drug abusers. BMF 1986;292:527-9.

2 Ronald PJM, Robertson JR, Roberts JJK. Risk taking behaviour on the decline in intravenous drug users. Br $\mathcal{F}$ Addict 1992;87:115-6.

3 Donoghoe MC, Stimson GV, Dolan KA. Syringe exchange in England: an overview. London: Tufnell Press, 1992.

4 Robertson JR. The Edinburgh epidemic: a case study. In: Strang J, Stimson G, eds. AIDS and drug misuse. London: Routledge, 1990.

5 Johnson AM. Home grown heterosexually acquired HIV infection. $B M \mathfrak{F}$ 1992;304:1125-6.

(Accepted 13 fuly 1993)

\section{Postmarketing study of cardiovascular adverse reactions associated with sumatriptan}

\section{J P Ottervanger, T B van Witsen, H A Valkenburg, B H Ch Stricker}

\section{Netherlands Centre for Monitoring of Adverse Reactions to Drugs, PO Box 5406, 2280 HK Rijswijk, Netherlands J P Ottervanger, medical officer \\ B H Ch Stricker, principal medical officer}

\section{University Centre of} Pharmacy, Section of Social Pharmacy, University of Groningen, Groningen, Netherlands $\mathrm{T} B$ van Witsen, research assistant

\section{Department of Epidemiology and} Biostatistics, Erasmus University Medical School, Rotterdam, Netherlands H A Valkenburg, professor

Correspondence to: Dr Stricker.

BMF 1993;307:1185

Prevalence of cardiovascular adverse reactions associated with sumatriptan in 1727 patients

\begin{tabular}{lc}
\hline $\begin{array}{l}\text { Adverse } \\
\text { reaction }\end{array}$ & No (\%) of patients \\
\hline Chest pain & $23(1 \cdot 3)$ \\
Palpitations & $6(0.35)$ \\
Hypertension & $2(0.12)$ \\
Syncope & $2(0.12)$ \\
Bradycardia & $1(0.06)^{\star}$ \\
\hline
\end{tabular}

*Also developed chest pain.
In May 1991 the serotonin-1 agonist sumatriptan was registered in the Netherlands for the treatment of acute attacks of migraine and cluster headache. In clinical trials sensations of pressure and tightness in the chest were experienced by $3 \%$ to $5 \%$ of patients, but no electrocardiographic evidence of cardiac ischaemia was found. ${ }^{1}$ Since being marketed sumatriptan has been associated with pain like angina pectoris ${ }^{2}$ and, when given subcutaneously, with chest pain accompanied by ST elevation in an electrocardiogram ${ }^{3}$ and with acute myocardial infarction in a previously healthy young women. ${ }^{4}$ We conducted a postmarketing study of the prevalence of cardiovascular adverse reactions associated with sumatriptan in cooperation with dispensing general practitioners.

\section{Patients, methods, and results}

In July 1992 all 687 dispensing general practitioners in the Netherlands were asked to provide the date of birth and sex of every person to whom sumatriptan had been dispensed since it was marketed in May 1991. They were also asked about the route of administration and whether they had observed any adverse reactions in their patients. To avoid bias no specific adverse reactions were mentioned in the questionnaire. The non-responders received two reminders, 11 and 17 weeks after the first request. Information was entered into a database and results were analysed by using two tailed $\chi^{2}$ and Student's $t$ tests.

The request yielded a response rate of $86 \%$ ( 589 general practitioners). Of these, 474 had dispensed sumatriptan on at least one occasion to a total of 1727 patients (414 men (24\%) and 1313 women (76\%)). Of the 1662 patients (96\%) with information about the route of administration, $683(41 \%)$ had taken sumatriptan orally, $842(51 \%)$ subcutaneously, and $137(8 \%)$ both orally and subcutaneously.

Of the 1727 patients, 185 (10.7\% (95\% confidence interval $9 \cdot 3 \%$ to $12 \cdot 1 \%$ )) had reported one or more adverse reactions, which resulted in a total of 247 adverse reactions. The mean age of the 1542 patients who did not report any adverse reactions was 43.8 (SD $11 \cdot 2)$, and $1172(76 \%)$ were women. The mean age of the 185 patients who reported adverse reactions was $43.3(11 \cdot 2)$, and $141(76 \%)$ were women. The most frequently reported adverse reactions were dizziness, nausea or vomiting, drowsiness or sedation, and chest pain, which were reported in $30,26,25$, and 23 patients respectively. Of the 183 patients who reported an adverse reaction and for whom date on administration were known, 81 (44\%) had been given sumatriptan The mean age of the patients was $43 \cdot 8$ years (SD 11.2). orally, $77(42 \%)$ subcutaneously, and 25 (14\%) both orally and subcutaneously. The corresponding figures for those who did not report any adverse reaction were $602(41 \%), 765(52 \%)$, and $112(8 \%)\left(\chi^{2}=10 \cdot 82, \mathrm{df}=2\right.$, $\mathrm{p}=0.004)$.

The table summarises the cardiovascular adverse reactions. Chest pain was reported by $19(83 \%)$ women and four $(17 \%)$ men, of whom eight (35\%) had taken sumatriptan orally, 11 (48\%) subcutaneously, and four $(2 \%)$ both orally and subcutaneously. The mean age of these patients was $44 \cdot 0(6 \cdot 4)$ years. Of the 1704 patients who did not report chest pain and for whom data on administration were known, 675 (41\%) had taken sumatriptan orally, $831(51 \%)$ subcutaneously, and $133(8 \%)$ ( $\chi^{2}$ with Yates's correction $\left.=2 \cdot 6, p=0 \cdot 27\right)$. Their mean age (43.8 (11.3) years) and the proportion of men and women $(410(24 \%)$ and $1294(76 \%)$ respectively) were not significantly different from the values in the group reporting chest pain. The prevalence of chest pain associated with sumatriptan was $1 \cdot 3 \%$ (95\% confidence interval $1 \cdot 2 \%$ to $1 \cdot 5 \%$ ).

\section{Comment}

Reports of angina pectoris and acute myocardial infarction with sumatriptan prompted us to estimate the prevalence of chest pain with this drug under everyday conditions. Dispensing general practitioners are a good source of information on adverse reactions to newly marketed drugs because of their excellent cooperation and direct access to data on dispensed drugs and disease in individual patients.

We intend to send a questionnaire to all patients who were treated with sumatriptan to investigate whether unreported adverse reactions occurred because the prevalence of chest pain in our study was lower than that in clinical studies. ${ }^{1}$ For an adverse reaction to be recognised, however, patients have to tell their general practitioner. If they fail to do so the prevalence of adverse reactions will be underestimated when reactions are mild.

A recent angiographic study suggested that sumatriptan causes coronary artery vasoconstriction. ${ }^{5}$ That chest pain was observed both in our study and in similar reports ${ }^{2}$ highlights the need for an extensive study, especially given the reported electrocardiographic abnormalities ${ }^{3}$ and myocardial infarction ${ }^{4}$ with sumatriptan. We therefore intend to set up a casecontrol study of patients with self reported chest pain to assess determinants of this adverse reaction.

We thank the dispensing general practitioners for their cooperation in this study.

1 Brown EG, Endersby CA, Smith RN, Talbot JCC. The safety and tolerability of sumatriptan: an overview. Eur Neurol 1991;31:339-44.

2 Stricker BHC. Coronary vasospasm and sumatriptan. BMF 1992;305:118.

3 Willet F, Curzen N, Adams J, Armitage $M$. Coronary vasospasm induced by subcutaneous sumatriptan. $B M F$ 1992:304:1415.

4 Ottervanger JP, Paalman HJA, Boxma GL, Stricker BHCh. Transmural myocardial infarction with sumatriptan. Lancet 1993;341:861-2.

5 Macintyre PD, Bhargava B, Hogg KJ, Gemmill JD, Hillis WS. Effect of subcutaneous sumatriptan, a selective $5 \mathrm{HT} 1$ agonist, on the systemic, pulmonary, and coronary circulation. Circulation 1993;87:401-5.

(Accepted 8 fuly 1993) 